\title{
Transient Dynamics Analysis of The Reachstacker Speader Based On ANSYS
}

\author{
Yu Feng SHU ${ }^{1}$,Si Li FAN ${ }^{1}$, Hai Ying ZHANG ${ }^{1}$ \\ ${ }^{1}$ Dong Guan Polytechnic, 523808, Dongguan, China.
}

\begin{abstract}
Reachstacker is an indispensable handling machinery, it will inevitably lead to unbalanced force at the job site. This paper does transient dynamics analysis for the spreader mechanism, which is one of the most significance key components. We get dynamic response of the spreader in lifting instant, results not only provide a reference for designers to understand the mechanical characteristics of spreader comprehensively, but also bedding for the future research.
\end{abstract}

\section{Introduction}

Reachstacker is widely used in container yard and marina. As one of the most significance key components, spreader is often in an unbalanced state during working,in particular the moment of the container has just been lifted ${ }^{[1]}$.Imbalance effect is more obvious with the unbalanced force, along with which the cargo and container will produce an acceleration, so the spreader will inevitably suffer large dynamic load. In this way, the maximum stress and displacement point of the mechanism may be constantly changing over time. In summary, in order to fully understand the mechanical properties of the spreader mechanism under dynamic load, static analysis is certainly not comprehensive. Spreader is work with telescopic, lateral displacement, rotation,etc, which can be applied to 20 and 40 -feet standard container. This paper take the $45 \mathrm{~T}$ reachstacker for example, rated load is $450 \mathrm{KN}$ and total weight is about $7500 \mathrm{KG}^{[2-3]}$. we select time integration method to calculate the transient response of spreader mechanism. Taking into account the effects between accuracy and solving speed, this paper sets the integration time step for $0.2 \mathrm{~s}$, the minimum time step is $0.05 \mathrm{~s}$ and the maximum value is $0.5 \mathrm{~s}$.

\section{Transient Dynamics Analysis}

\subsection{Finite element model}

This paper selects the 10 nodes solid 187 unit,which has strong adaptability to irregular structure ${ }^{[4]}$. Weighing the effect between accuracy and model size in meshing, we can set individual size for different parts in the element size dialog box ${ }^{[2]}$. So the spreader modelis being divided into total of 340,033 nodes and 171,269 units. The spreader's main parts are manufactured by high-strength steel,therefore, itsmechanical properties are as follows:(Elastic modulus) $E=211 \mathrm{GPa}$,(Poisson's ratio) $\mu=0.3$, (Density) $\rho=7850 \mathrm{~kg} / \mathrm{m}^{3}$, (Constant mass damper) $\alpha=0.1693, \quad$ (Constant stiffness damper) $\beta=0.00046$. Figure 1 shows the finite element model of spreader.

\subsection{Load Step}

As we know, reachstacker spreader contains four locking pins, and load increasing of each locking pin is always a certain process. We assume that locking pin came into contact with container surfacefrom the moment $t_{0}=0$, field tests show that container is about to leave ground from the moment $t_{1}=1.2 \mathrm{~s}$, in other words, total weight of cargo and containers equals the force of four locking pins. We select"Ramped Load"in the "Full Transient Options"dialog box for this process, which intended load is gradually increasing. This paper selects $1.5 \mathrm{~s}$ foranalysis process, and we change"Ramped Load" into "Stepped Load"in the second load step setting options, which meansload is constant in this period. Load time history of the single locking pin surface is shown in Figure 2. 


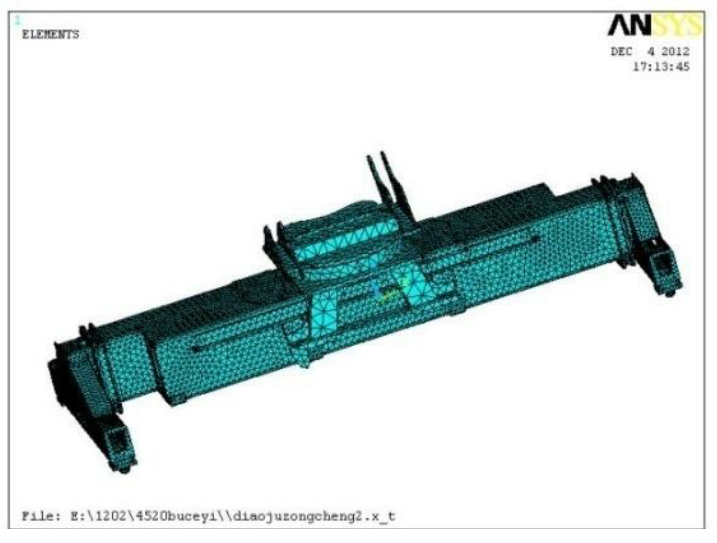

Figure1. Finite element model

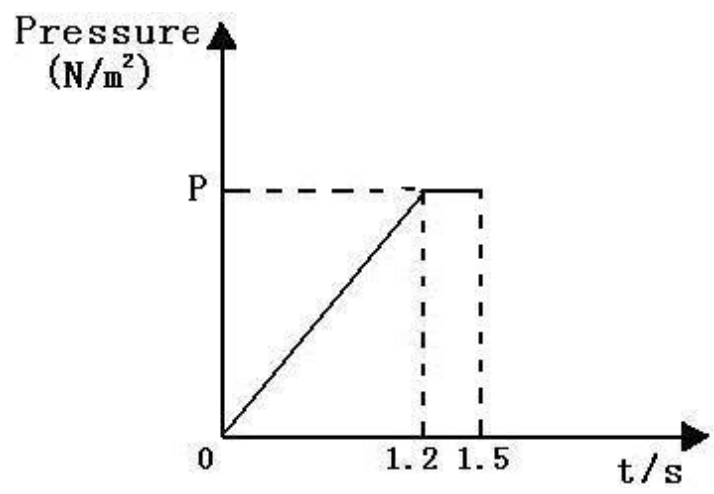

Figure 2.Load time history

\subsection{Analysis Cases}

There is no doubt that spreader force under 40 feet container conditions is even worse than 20 feet $^{[5]}$. In order to examine the further dynamic response of spreader mechanism and explain the body harm caused by partial load in quantifiable form,taking into account that left and right of spreader is $800 \mathrm{~mm}$, front and rear is $100 \mathrm{~mm}$, this paper does transient dynamic analysis for spreader mechanism under four typical conditions withrated load, as shown in Table 1.

Table 1. Analysis cases

\begin{tabular}{|c|c|c|c|c|c|}
\hline & $\begin{array}{c}\text { Load } \\
/ \mathbf{T}\end{array}$ & $\begin{array}{c}\text { Container } \\
\text { specification } \\
\text { /feet }\end{array}$ & $\begin{array}{c}\text { Rotatio } \\
\mathbf{n} /{ }^{\circ}\end{array}$ & $\begin{array}{c}\text { Left and } \\
\text { right } \\
\text { sideswa } \\
\mathbf{y} / \mathbf{m}\end{array}$ & $\begin{array}{c}\text { Front } \\
\text { and rear } \\
\text { sideswa } \\
\mathbf{y} / \mathbf{m}\end{array}$ \\
\hline $\mathbf{1}$ & 45 & 40 & 0 & 0 & 0 \\
\hline $\mathbf{2}$ & 45 & 40 & 0 & 800 & 0 \\
\hline $\mathbf{3}$ & 45 & 40 & 0 & 0 & 100 \\
\hline $\mathbf{4}$ & 45 & 40 & 0 & 800 & 100 \\
\hline
\end{tabular}

\subsection{Load Determination}

It is necessary to consider the gravity due to huge structure. Firstly, we should define gravitational acceleration in -Zdirection; Secondly, the force of each locking pin will be converted into pressure, which should be applied to the plane of locking pin. Four locking pins are numbered in this paper, and force of the locking pin No.1 is F1, pressure is P1, force of the locking pin No.2 is F2, pressure is $\mathrm{P} 2$, and so on ${ }^{[6-7]}$. Number of locking pin is shown in Figure 3.

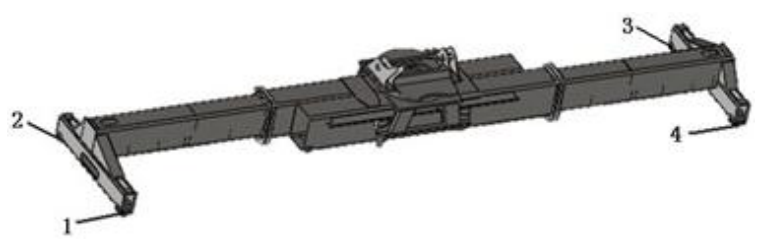

Figure 3.locking pin number

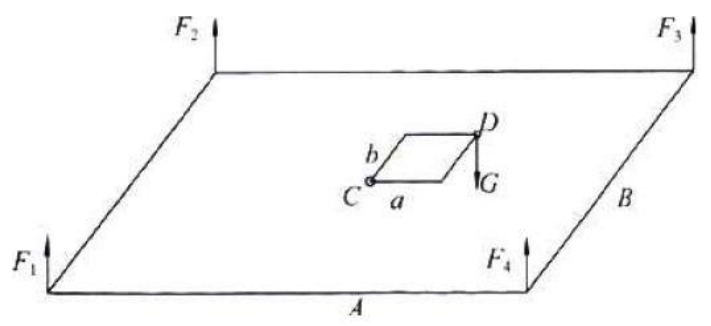

Figure 4.Computing model

Allcases are partial load condition except 1, sowe need to calculate the force on each locking pin, following relationship can be easily obtained according to the knowledge of mechanical balance and computing model shown in Fig.4:

$$
\begin{gathered}
G=m g \\
F_{i}=P_{i} S
\end{gathered}
$$

$$
F_{1}+F_{2}+F_{3}+F_{4}=G
$$

$$
\left(F_{1}+F_{2}\right)\left(\frac{A}{2}+a\right)=\left(F_{3}+F_{4}\right)\left(\frac{A}{2}-a\right)
$$

$\left(F_{1}+F_{4}\right)\left(\frac{B}{2}+b\right)=\left(F_{2}+F_{3}\right)\left(\frac{B}{2}-b\right)$

$G$ : Total weight of cargo and container.

$F_{i}$ : Force of the locking pin numbered $i$.

$P_{i}$ : Pressure of the locking pin numbered i.

$S$ : Bearing area of the locking pin.

$A$ : Length of 40 feet container.

$B$ : Width of 40 feet container.

$a$ : Displacement of lateral partial load.

$b$ : Displacement of longitudinal partial load ${ }^{[8]}$.

Among the parameters above:

$m=45 t, \quad S=2832.69 \mathrm{~mm}^{2}$

$A=11985 \mathrm{~mm}, \quad B=2259 \mathrm{~mm}$.

$a$ and $b$ values of all cases are listed in Table 2. 
Table 2. $a$ and $b$ values of all cases

\begin{tabular}{|c|c|c|c|c|}
\hline & $\begin{array}{c}\text { Case } \\
\mathbf{1 ( m m )}\end{array}$ & Case2(mm) & Case3(mm) & Case4(mm) \\
\hline$a$ & 0 & 800 & 0 & 800 \\
\hline$b$ & 0 & 0 & 100 & 100 \\
\hline
\end{tabular}

We can get the pressure values of each locking pin via solving these equation, as shown in Table 3.

Table 3. Pressure values of each locking pin in different cases

\begin{tabular}{|l|l|l|l|l|}
\hline & $P_{1}\left(\mathrm{~N} / \mathrm{m}^{2}\right)$ & $P_{2}\left(\mathrm{~N} / \mathrm{m}^{2}\right)$ & $P_{3}\left(\mathrm{~N} / \mathrm{m}^{2}\right)$ & $P_{4}\left(\mathrm{~N} / \mathrm{m}^{2}\right)$ \\
\hline $\mathbf{1}$ & 38920602 & 38920602 & 38920602 & 38920602 \\
\hline $\mathbf{2}$ & 38920602 & 28474378 & 49366826 & 38920602 \\
\hline $\mathbf{3}$ & 38920602 & 38920601 & 45803553 & 32037651 \\
\hline $\mathbf{4}$ & 38920602 & 28474378 & 56249777 & 32037651 \\
\hline
\end{tabular}

\section{Solution and Analysis}

$\mathrm{X}$ is perpendicular to the direction of beam end face, $\mathrm{Y}$ is perpendicular to the direction of beam cross-section, $\mathrm{Z}$ is the direction of gravity ${ }^{[9]}$. This paper study the 134194 node which lies in the vicinity of the maximum displacement, we can get $\mathrm{X} 、 \mathrm{Y} 、 \mathrm{Z}$ displacement variation history of 134194 node under all cases. As a result of space limitations, we only showpart of the calculation results.

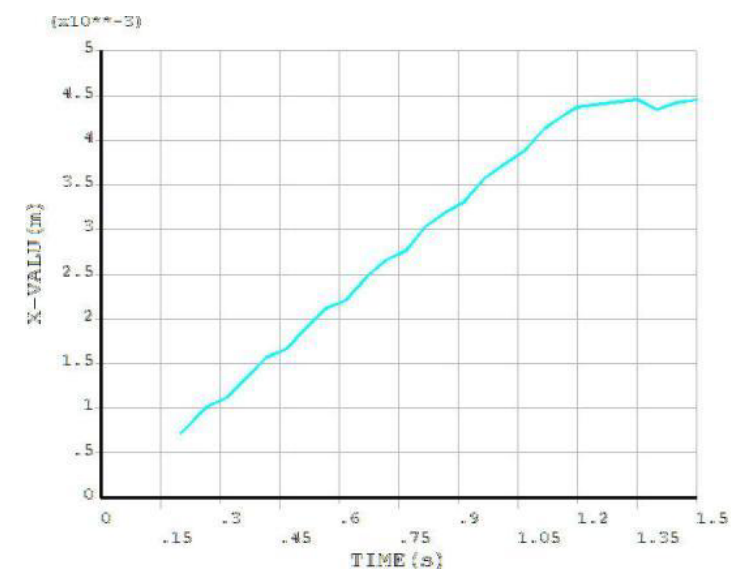

(a) $\mathrm{X}$ displacements variation history of case 1

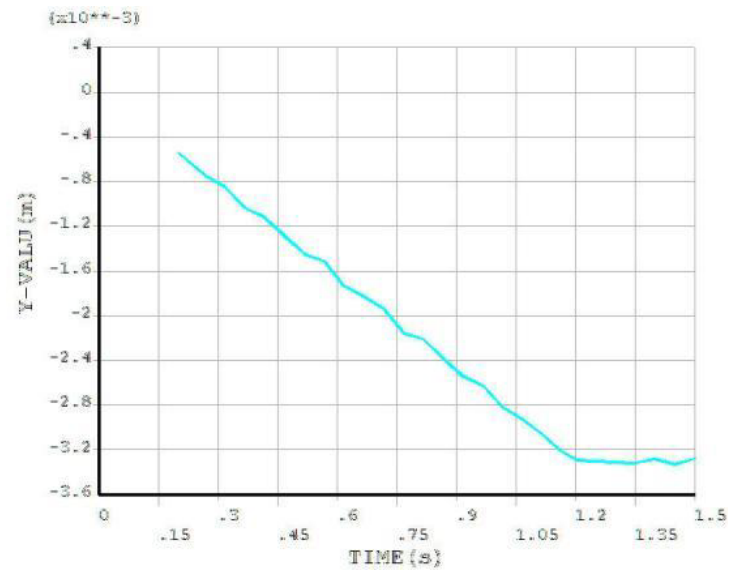

(b) Y displacements variation history of case 1

Figure 5. X、Y displacements variation history of case 1

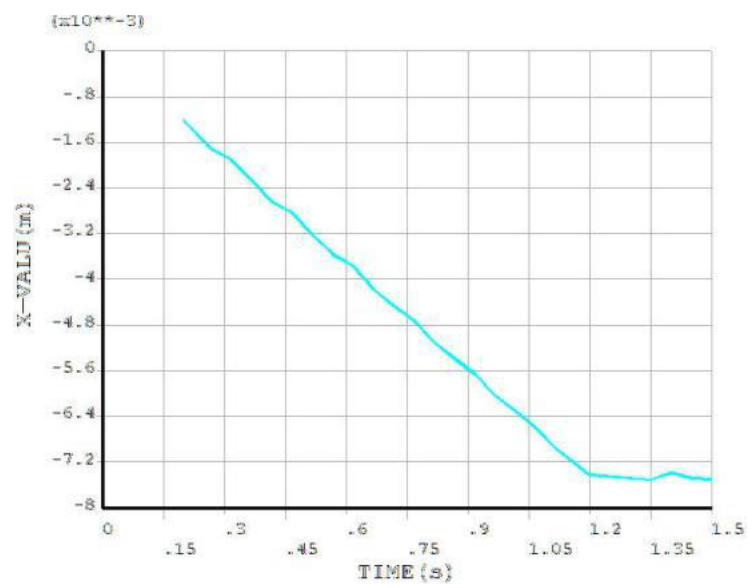

(a) X displacements variation history of case 4

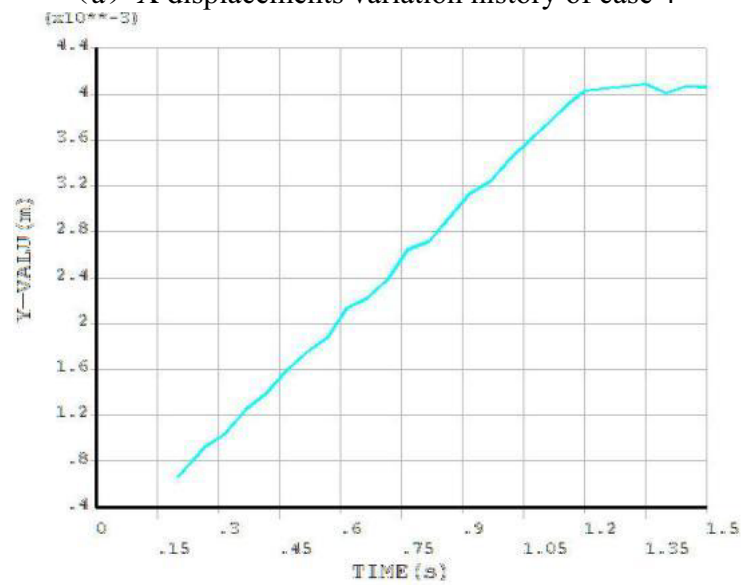

(b) Y displacements variation history of case 4

Figure 6.X、Y displacements variation history of case 4

Seen from the calculation results, the maximum stress under all cases are less than the material yield limit 600Mpa. Apart from a few high-stress areas, overall stress of spreader box skeleton is low $(<180 \mathrm{MPa})$, which fully reflects the excellent mechanical properties of high strength steel ${ }^{[5]}$. The maximum stress are basically the same position under all cases, lying on the head ribs of beams body. Furthermore, stress concentration occurs in the vicinity of maintenance windows because of structural mutation.

Forcase 1, with the increase of ramped loading, $\mathrm{X}$ 
displacement is increasing, $\mathrm{Y}$ and $\mathrm{Z}$ displacements are constantly decreasing, with the increase ofstepped loading, they have tended to be a certain value; with the ramp load applied in Partial load conditions, $Y$ displacement is increasing, $\mathrm{X}$ and $\mathrm{Z}$ displacements areconstantly decreasing, they have tended to be a certain valuewith the increase of stepped loading.Table 4showsthe gradient of three maximum stress values and displacementswhich lie in partial load conditionbyquantifiable form with respect to case 1 .

Table 4.Gradient of the maximum stress and displacement

\begin{tabular}{|c|c|c|l|c|}
\hline Case & $\sigma_{\max }(M P a)$ & $\begin{array}{c}\text { Stress } \\
\text { gradient }\end{array}$ & $D_{\max }(m)$ & $\begin{array}{c}\text { Incremen } \\
\text { tal value }\end{array}$ \\
\hline $\mathbf{2}$ & 540 & $19.5 \% \uparrow$ & 0.039311 & $16.3 \% \uparrow$ \\
\hline $\mathbf{3}$ & 516 & $14.2 \% \uparrow$ & 0.042642 & $26.1 \% \uparrow$ \\
\hline $\mathbf{4}$ & 507 & $12.2 \% \uparrow$ & 0.048142 & $42.4 \% \uparrow$ \\
\hline
\end{tabular}

\section{Summary}

The maximum stress are basically the same position under all cases, lying on the head ribs of beams body, there are large stress concentration in the vicinity of maintenance window.

$\mathrm{X}$ displacement contributes to the maximum deformation is larger than $\mathrm{Y}$ and $\mathrm{Z}$ under No partial load conditions.

$\mathrm{Y}$ displacement contributes to the maximum deformation is larger than $\mathrm{X}$ and $\mathrm{Z}$ under partial load conditions.

To reduce the maximum deformation of spreader mechanism under partial load conditions, designers should try to increase the stiffness which perpendicular to the direction of telescopic beam cross-section.

\section{References}

1. Li Zhang,Jianlong Lin,Huiyu Xiang. Modal analysis and Experiment(Tsinghua UniversityPress, Beijing 2011), p,56-69.

2. Baz,A,Ruzzene,M. Dynamic stability of Periodic shells with moving loads[J]. Journal of Sound and Vibration, 2006,830-844.

3.Diqing Wu, Yanlin Lu, Wanbin Chen. Modal analysis and optimization of forklift frame based on finite element: submitted to Journal of Light Industry Machinery (2008), p, 48-50.

4.Zhu Rensheng, Zheng Zhenzhen, Liu Yongmei.Finite Element Analysis for MW Wind Turbine

Tower[J]. Applied Mechanics and Materials, 2011:130-134.

5.Wei Zhou.Strength calculation and modal analysis of subway stainless steel body: submitted to Journal of Urban Rapid Rail Transit (2007), p, 47-49.

6.Shenbo Yan. Optimization Design of Reachstackers's boom: Master,submitted to Daqing Petroleum Institute (2006), p, 52-54.

7.Altintas,Y,Y.Cao.Virtual design and optimization of machine tool spindles. Annals-Manufacturing Technology, 2005,54(1):379-382.

8. Liqun Wu, Wanrong Wu. Application of Pro / E in dynamic performance analysis of the hydraulic excavator: submitted to Mechanical Research and Application (2007), p, 83-84.

9. YE Meixin, HUANG Qiong, WU Qinqin. Analysis of steel-concrete composite structure with overlap slab of Xingguang bridge, 2007:121-124. 